Implementing an interprofessional first-year teamwork project: some key reflections

Susan M. McNaughton

School of Interprofessional Health Studies

Auckland University of Technology

Author note

Susan M. McNaughton, School of Interprofessional Health Studies, Auckland University of Technology.

Correspondence concerning this article should be addressed to Susan McNaughton, A25, Akoranga Campus, Auckland University of Technology, Private Bag 92006, Auckland 1142, New Zealand. Contact: smcnaugh@aut.ac.nz

Key words: Interprofessional education, teamwork, first-year, blended learning, administration 


\title{
IMPLEMENTING AN INTERPROFESSIONAL FIRST-YEAR TEAMWORK PROJECT: SOME KEY REFLECTIONS
}

\begin{abstract}
Implementing an interprofessional teamwork project for first-year students presents pedagogical and practical challenges. While transferable skills and attributes are important, engagement of students with limited professional experience in teamwork depends on relevance to current learning needs. This report outlines principles learned from planning and implementing a teamwork project for an interprofessional health administration and service development course. Practicing interprofessional teamwork as leaders and teachers, aligning with previous, current and future teamwork content and processes, and responding to student feedback and achievement, have been key factors in shaping the project over three semesters. Face to face and online interprofessional teamwork learning has necessitated developing resources that support self-direction, using familiar technology and providing enabling physical environments. Implications for first-year interprofessional teamwork are that structured wellresourced processes, responsiveness and alignment of learning all improve student outcomes.
\end{abstract}

Keywords: Interprofessional education, teamwork, first-year, e-learning, health administration 


\section{INTRODUCTION}

Students in practice settings benefit from and respond positively to interprofessional teamwork, especially simulation or problem-based collaborative learning (Hayashi et al., 2012). Since professional identities can create barriers to teamwork, interprofessionalism must be actively cultivated (Robichaud et al., 2011). Howard, Ryan, Eudy, Mosser, and Boyd (2010) have suggested that the interprofessional learning necessary for students entering complex healthcare contexts should begin early, but this area is under-researched (Hayashi et al., 2012). This paper shares lessons learned in implementing teamwork in a first-year interprofessional course.

The course, Health Administration and Service Development (HASD) was introduced in 2011 for non-clinical health students completing a New Zealand university Bachelor of Health Science degree in health promotion or policy, public health, or conjoint health and business or health and sport and recreation. Each semester, around fifty students take the HASD course which blends on-campus and online requirements and follows a first semester of shared papers with all health students. HASD involves six weeks studying wider healthcare influences and case studies, then six weeks of interprofessional teamwork in face to face and online groups of six. Teams produce an online report on the structure, governance and operation of a health service organisation and present a plan for a possible improvement to its services at a class symposium. 


\section{LESSONS LEARNED}

\section{Practice what you preach}

Designing, planning and implementing HASD has benefitted significantly from teamwork by three women with interprofessional tertiary teaching, clinical and/or management experience in medicine, nursing and oral health. Communication networks with employers have produced a strong focus on transferable graduate-relevant capacities. Close collaboration with the coordinator of a first semester shared paper that introduces students to interprofessional teamwork has been essential to continuity of learning.

HASD introduces students to the New Zealand health system, including international comparisons, politics, health law, ethics, the wellness industry and management. Interprofessional teaching by guest specialists rates highly in formal student feedback, but is logistically and pedagogically difficult. Becoming familiar with guests' lecture content to enable its exploration in tutorials, and making practice connections through case studies and the team project, have improved student integration of the diverse content.

\section{Align teamwork content and assessment}

Alignment of learning provides a sense of continuity, purpose and security for students with mostly undefined professional identities. Students unable to see the relevance of course learning objectives or to link these to specific course activities may participate selectively or disengage altogether. Graduate capacities must be balanced with teamwork skills that assist 
immediate tertiary learning, such as the self-awareness of strengths and weaknesses, verbal communication and respect for others recommended by Leggat (2007).

The course focuses on two forms of alignment. Alignment with previous learning includes: extending skills such as constructive communication and editing; using similar team structures with greater autonomy; progressing to individual summative reflections on performance. Collaborative report writing and verbal presentations align with assessments in second and third year papers and thus with future learning. Robichaud et al. (2012) have noted that students value communicative, collaborative and interpersonal skills in themselves and others in real world problem-solving, but want credit for contributing relevant specialist knowledge. HASD introduces new, generally applicable content allowing students without professional experience to contribute equitably, and teamwork content and processes constitute half the course grades. Reported student teamwork problems of unrealistic expectations and uncooperative teammates (Hayashi et al., 2012) have been documented amongst practitioners (Kvarnstrom, 2008). We believe that early exposure to teamwork with equitable accessible processes, safe boundaries and feedback opportunities assists students in learning to manage inherent teamwork difficulties.

\section{Provide resources and support}

We have found that good resources and support make teamwork enjoyable and sustainable, encouraging self-direction. Consistent with other published successes (Howard et al., 2010), we have developed an extensive online bank of specialised resources used to develop information skills, allowing equitable access, encouraging team information sharing and providing unfamiliar 
specific knowledge that enables all students to participate effectively. Team grade eligibility in HASD is dependent on individual passes, and collaboration and integration of both content and processes is assessed. Tseng, Wang, Ku, and Sun (2009) have found this encourages selfdirection, making room for individual research excellence while penalising non-contributors.

Combining online and face to face team meetings has improved accessibility and personal contact, promoting clear communication, early acquaintance, trust and good organization. These factors have all been shown to correlate with online team student satisfaction, and to simulate graduate interprofessional teamwork through accountability and transparent participation (Tseng et al., 2009). Student feedback has been positive and consistently attributes poor team function to human, not technical issues. Summative reflections have indicated that face to face meetings enhance content engagement and online interactions. This may reflect students listening, negotiating and receiving support for decision-making (Leggat, 2007).

As noted by Howard et al. (2010), the physical environment profoundly affects interprofessional learning. When HASD was located in a lecture theatre, the immobile seating and impersonality made team discussion very stilted. Many teams stopped meeting as scheduled, making teacher support difficult. The current classroom has modular furniture, encouraging collaboration and interaction. 


\section{Respond to student feedback}

Responding to feedback demonstrates that students' interprofessional experiences and expectations are valued (Howard et al., 2010). One example from HASD relates to unstated online expectations which allowed disengaged team members to remain invisible. Student feedback confirmed the findings of Schultz, Wilson, and Hess (2010): disengagement that leads to team underperformance is a concern for autonomous students, and unfair grading is universally disliked. Complaints have reduced since online expectations and individual grades were introduced. Another example would be provision of templates for tasks students found time-consuming.

Informal feedback has raised concerns about critiquing the contributions of relative strangers and poor contributors' behaviour, problems also noted by Schultz et al. (2010). Since knowing other team members more personally improves teamwork satisfaction (Tseng et al., 2009), smaller tutorial groups are now being trialled during case studies to encourage this.

\section{Respond to student outcomes}

Responding to student outcomes has included re-evaluating processes associated with lower grades, for example, demonstrating leadership. Robichaud et al. (2012) noted that horizontal leadership enhanced motivation and engagement in student interprofessional teams. The symposium where all team members must present is an attempt to encourage this. Powerful indicators of whether teamwork benefits or disadvantages certain students can emerge from reflective assessments, which also have future learning relevance. Elements of 
conflict and vulnerability have surfaced in the HASD summative formal reflections prompting changes to teamwork processes and teaching.

\section{CONCLUDING COMMENTS}

While definitive outcome benefits from early interprofessional teamwork remain unproven (Hayashi et al., 2012), we believe it should benefit students' current learning and encourage positive attitudinal shifts in clinical and non-clinical students. If interprofessional teamwork is to become a sustainable graduate practice, alignment with students' previous and future learning is essential. In Health Administration and Service Development we have found that structured, well-resourced first year online and face to face teamwork learning, interprofessional teaching, and specific modifications to processes in response to student feedback and achievement has improved outcomes.

\section{Declaration of Interest}

The author reports no conflict of interest. The author alone is responsible for the content and writing of the report. 


\section{REFERENCES}

Hayashi, T., Shinozaki, H., Makino, T., Ogawara, H., Asakawa, Y., Iwasaki, K., ... Watanabe, H. (2012). Changes in attitudes toward interprofessional health care teams and education in the first- and third-year undergraduate students. Journal of Interprofessional Care, 26, 100-107. doi:10.3109/13561820.2011.644355

Howard, D., Ryan, K., Eudy, R., Mosser, G., \& Boyd, K. (2010). Critical decision points in designing inter-professional education. The Journal of Health Administration Education, $27,135-144$.

Kvarnstrom, S. (2008). Difficulties in collaboration: A critical incident study of interprofessional healthcare teamwork. Journal of Interprofessional Care, 22, 191-203. doi:10.1080/13561820701760600

Leggat, S.G. (2007). Teaching and learning teamwork: Competency requirements for healthcare managers. The Journal of Health Administration Education 24, 135-149.

Robichaud, P., Saari, M., Burnham, E., Omar, S., Wray, R.D., Baker, R., \& Matlow, A.G. (2012). The value of a quality improvement project in promoting interprofessional collaboration. Journal of Interprofessional Care, 26, 158-160. doi:10.3109/13561820.2011.637648

Schultz, J.L., Wilson, J.R., \& Hess, K.C. (2010) Team-based classroom pedagogy reframed: The student perspective. American Journal of Business Education, 3(7), 17-24.

Tseng, H., Wang, C-H., Ku, H-Y., \& Sun, L. (2009). Key factors in online collaboration and their relationship to teamwork satisfaction. The Quarterly Review of Distance Education, 10, 195-206. 